\title{
Correction to: Fiber Orientation Effects in Fused Filament Fabrication of Air-Cooled Heat Exchangers
}

\author{
T. MULHOLLAND $®,{ }^{1,2}$ S. GORIS, ${ }^{1}$ J. BOXLEITNER, ${ }^{1}$ T.A. OSSWALD,${ }^{1}$ \\ and N. RUDOLPH ${ }^{1}$ \\ 1.-Department of Mechanical Engineering, University of Wisconsin, Madison, WI, USA. \\ 2.—e-mail: tmulholland@wisc.edu
}

Correction to: JOM, Vol. 70, No. 3, 2018

https://doi.org/10.1007/s11837-017-2733-8

The authors would like to correct their funding information as follows:

\section{ACKNOWLEDGEMENTS}

The research was done at the University of Wisconsin-Madison. The information, data, or work presented herein was funded in part by the Advanced Research Projects Agency-Energy (ARPAE), U.S. Department of Energy, under Award No. DE-AR0000573. The views and opinions of authors expressed herein do not necessarily state or reflect those of the United States Government or any agency thereof. 